Diabetologia 9, 447-452 (1973)

(C) by Springer-Verlag 1973

\title{
In Vitro Studies on Insulin Secretion in the Genetically Obese Mouse
}

\author{
A. Beloff-Chain, M.E. Newman and K.R.L. Mansford \\ Department of Biochemistry, Imperial College, London, SW7 2AY and Beecham Research Laboratories, Brockham \\ Park, Surrey, England \\ Received: April 2, 1973, and in revised form: June 25, 1973
}

\begin{abstract}
Summary. Pancreatic insulin content and insulin secretion from the pancreas of obese mice fed ad lib (ob/ob), obese mice maintained on a restricted diet (ob/ob RD) and lean mice has been studied using incubated pieces of pancreas in vitro and in a perifusion system. The ob/ob mice pancreas contained approximately twice as much insulin as the lean mice pancreas, whereas the ob/ob RD mice had a normal insulin content. Increasing the glucose concentration had a marked and prolonged stimulating effect on insulin secretion in the pancreas of the ob/ob and ob/ob RD mouse, but not in the lean mouse. Leucine stimulated insulin secretion in all three groups of animals both in the absence and presence of glucose in a biphasic manner; in the presence of glucose
\end{abstract}

the insulin secreted from the pancreas of the ob/ob and ob/ob RD mice was abnormally high. Arginine stimulated insulin secretion from the lean mouse pancreas in the absence of glucose, whereas in the obese mouse pancreas stimulation was observed only in the presence of glucose, and the effect increased with increasing glucose concentration. The large amounts of insulin which can be secreted by the pancreas of the ob/ob and ob/ob RD mice under stimulation suggest that an abnormal response of the pancreas to biological stimuli of insulin secretion could be a primary defect in these animals.

Key words: Insulin, obese mice, pancreas, glucose, amino acids.
The recessively inherited obese hyperglycaemic syndrome in mice, which was first described by Ingalls, Dickie and Snell (1950) [16], has been very widely investigated, but the primary defect in these animals has not been established. It has been suggested by some investigators [12] that the hyperinsulinaemia caused by an abnormal secretion of insulin from the $\beta$ cells [22] could be a primary defect leading subsequently to the other characteristics of the syndrome e.g. hyperphagia, obesity, insulin resistance etc. $\mathbf{E x}$ cessive insulin secretion could be either due to the greater sensitivity of the $\beta$ cells in the obese mice to normal biological stimulation or to excessive stimulation by some unknown factor or a combination of these two.

In order to try to gain further insight into this problem it was decided to carry out an investigation on factors influencing insulin secretion in the obese mice and their lean littermates. To separate the effects of hyperphagia and concomitant hyperglycaemia on insulin secretion from primary differences in the response of the pancreas of obese mice, obese mice fed ad libitum have been compared with those maintained on a restricted diet as described by Abraham and Beloff-Chain (1971) [1]. In the present communication the total content of insulin in the pancreas of the obese mice fed $a d l i b$ and those kept on a restricted diet is compared with the total insulin content in the pancreas of the lean littermates. The effects on insulin secretion in vitro of glucose, amino acids and of theophylline have also been studied in these three groups of animals.

The investigation was carried out using in vitro incubated pieces of pancreas [7] or using a perifusion technique [5] in which a continuous flow of medium is passed over small pieces of pancreas and collected for insulin assay at set time intervals, the stimulant being added to the perifusion fluid after a suitable time period.

No attempt has been made in the present study to quantify the absolute differences in insulin secretion from pancreases of different groups of animals. This cannot be done by expressing the results as per weight of pancreas, as the number and size of the $\beta$ cells present is unknown; however the technique used is adequate to study the effects of various stimuli on insulin secretion, as each piece of pancreas acts as its own control.

\section{Methods \\ Mice}

The origin of the obese mouse colony bred in this Department and the feeding of these animals has been previously described [1]. 3-4 months old female mice were used. The obese mice fed ad libitum are referred to as $\mathrm{ob} / \mathrm{ob}$ and those maintained on a restricted diet as ob/ob RD.

\section{Determination of Total Insulin in the Pancreas}

Total pancreatic insulin was determined by a modification of the method of Kenny (1955) [17], as described by Findlay, Rookledge, Beloff-Chain and Lever (1973) [11].

\section{Preparation of Pancreas Pieces}

Mice were killed by cervical dislocation, their pancreas removed and washed in Krebs Ringer bicarbonate 
buffered medium $\mathrm{pH}$ 7.4, then blotted and weighed. Each pancreas was cut up into pieces weighing $5-10$ mg.

\section{Incubation of Pancreas Pieces}

Four pancreas pieces were placed in vessels which were a modification of those described by Coore and Randle (1964) [7], consisting of perspex rings, $1 \mathrm{~cm}$ in diameter, and $0.6 \mathrm{~cm}$ in length, closed at one end with a circle of nylon gauze. The vessels were immersed in $5 \mathrm{ml}$ of Krebs Ringer bicarbonate buffer at $\mathrm{pH} 7.4$ gassed with $95 \% \quad \mathrm{O}_{2} / 5 \% \quad \mathrm{CO}_{2}$ containing $2 \mathrm{mg} / \mathrm{ml}$ albumin in scintillation vials and shaken in a metabolic incubator at $37^{\circ}$. Each incubation period was $20 \mathrm{~min}$, after which the vessels containing the pancreas pieces were transferred to another vial containing freshly gassed medium.

\section{Results and Discussion}

Where statistical analyses have been applied the student's ' $t$ ' test was used.

\section{a) Pancreatic Insulin Content}

The results given in Table 1 show the insulin content of the pancreas of the ob/ob, the ob/ob RD and the lean mice. There were 6 mice in each group and two to four analyses were carried out in each assay. The results show that the total weight of the pancreas did not differ significantly in these groups of animals. The obese mice fed ad libitum contained more than twice as much insulin as the lean mice, but the obese mice which had been maintained on a restricted diet did not have a significantly higher insulin content than that observed in the lean mice. Similar differences in

Table 1. Insulin content of pancreases from $o b / o b, o b / o b R D$ and lean mice. Results are the mean of six animals in each group, $\pm S E M$. Difference between obese and lean mice significant when $p<0.05$

\begin{tabular}{|c|c|c|c|c|c|}
\hline Animal & $\begin{array}{l}\text { Wt of pancreas } \\
\mathrm{mg}\end{array}$ & $\begin{array}{l}\text { mU insulin } \\
\text { per pancreas }\end{array}$ & $p$ & $\begin{array}{l}\mathrm{mU} \text { insulin per } \mathrm{mg} \\
\text { wet wt. pancreas }\end{array}$ & $p$ \\
\hline $\begin{array}{l}\text { Lean } \\
\text { ob/ob } \\
\text { ob/ob RD }\end{array}$ & $\begin{array}{l}298 \pm 18 \\
282 \pm 23 \\
272 \pm 17\end{array}$ & $\begin{array}{r}982 \pm 161 \\
2249 \pm 316 \\
1213 \pm 254\end{array}$ & $\begin{array}{l}0.01 \\
\text { NS }\end{array}$ & $\begin{array}{l}3.49 \pm 0.27 \\
8.46 \pm 2.04 \\
4.35 \pm 0.63\end{array}$ & $\begin{array}{l}0.05 \\
\text { NS }\end{array}$ \\
\hline
\end{tabular}

The transfer of the pancreas into fresh medium at twenty minute intervals appears to overcome the problem of the breakdown of insulin by proteolytic enzymes (some preliminary experiments carried out with the proteolytic enzyme inhibitor trasylol gave similar results) and also prevents the inhibition of insulin secretion by an accumulation of insulin in the medium.

\section{Perifusion of Pancreas Pieces}

The technique used was a modification of that described by Burr et al. (1969) [5]. Ten pieces of pancreas weighing approximately 5-10 $\mathrm{mg}$ each were placed on Millipore filters which were inserted into water tight holders connected to a resevoir of medium by rubbertubing. The medium was sucked through the filters by a peristaltic pump and collected in test tubes. The rate of flow was as indicated in the legends to the figures. The insulin secreted at 5 min intervals was determined.

\section{Insulin Assay}

$50 \mu \mathrm{l}$ samples were assayed for insulin and each analysis was carried out in triplicate. The immunoassay technique used was similar to that described by Heding (1971) [13] for glucagon assay. Assay samples were incubated overnight at $4^{\circ} \mathrm{C}$ with equal volumes of ${ }^{125} \mathrm{I}$ labelled insulin and anti-insulin serum at appropriate dilutions. The insulin antibody complex was precipitated with absolute ethanol and counted in a Tracerlab gamma counter. the insulin content of the pancreas from ob/ob mice fed ad libitum in this age group have been reported previously $[11,12,25]$. All these investigators confirmed the high pancreatic immunoreactive insulin content in genetically obese mice which was first reported by Wrenshall, Andrews and Mayer (1955), using a bioassay for insulin. The very marked hyperinsulinaemia in the ob/ob animals, as has been pointed out previously [12], is disproportionate to the two to four fold increase in pancreatic insulin and cannot be explained by hyperglycaemia, which is an extremely variable factor in the obese mouse. The present experiments show that restricting the diet of the ob/ob mice reduced the insulin level of the pancreas to values not significantly higher than those observed in lean animals. It has already been shown that obese mice on a restricted diet have elevated serum insulin levels, although not as high as in the ob/ob mouse fed ad libitum [2].

\section{b) Response of the Pancreas}

There is considerable histological evidence in the literature that there are abnormalities of the obese mouse pancreas which indicate endocrine hyperactivity [11]. The histological changes in the pancreas associated with obesity and evidence for the increased synthesis and secretion of insulin in obese mice have been discussed $[4,14]$. Furthermore, it has been reported [24] that the effect of restricted caloric intake in the ob/ob mice restores the appearance of the pancreas to a more normal cellular composition. It was therefore of interest to see whether the response of the 
pancreas to glucose stimulus and to other known stimuli would be the same in the ob/ob RD mice as in the ob/ob mice, or whether the pancreas would respond similarly to the lean mouse pancreas.

(i) Influence of glucose concentration. Fig. 1 shows the results of experiments in which pieces of pancreas were incubated in different concentrations of glucose; the amount of insulin secreted in three twenty minute periods and in some experiments for a further thirty minute period was measured by transferring the pieces to fresh medium at the end of these periods and assaying the insulin secreted in each of the incubation vessels. The results show that in all cases the maximum rate of insulin secretion was obtained in the first $20 \mathrm{~min}$, as previously reported [9], and in most experiments the rate of insulin secreted in the second and third twenty

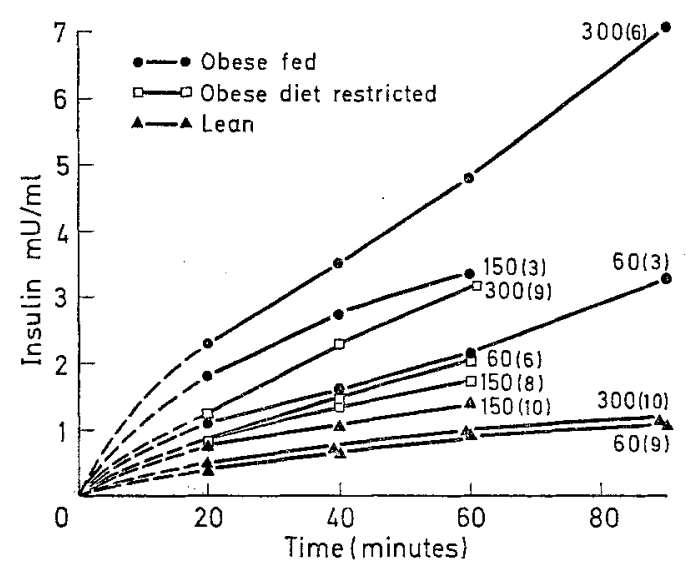

Fig. 1. Rate of insulin secretion from pieces of pancreas of ob/ob, ob/ob RD and lean mice in the presence of varying glucose concentrations. Experimental conditions given in the text. Main numbers refer to glucose concentrations. Each point refers to mean of the number of experiments given in parenthesis

minute periods of incubation was fairly constant. This could be explained by a non specifie leakage of insulin [15] or by a labile compartment of insulin from which secretion is rapidly stimulated on exposure to glucose [8]. The second explanation is more probable in view of the fact that a glucose stimulatory effect was apparent in the first twenty minute period. Due to the high biological variation in the amount of insulin secreted by the pancreas of different animals the statistical evaluation of the data is unreliable, and only mean values are presented in Fig. 1. However the results indicate that the rate of insulin release in lean mice when the glucose concentration was raised from 60 to $150 \mathrm{mg} \%$, was increased, but in the presence of $300 \mathrm{mg} \%$ glucose the rate of insulin release was equivalent to that at $60 \mathrm{mg} \%$. With the obese mouse pancreas increasing the glucose concentration from 60 to $150 \mathrm{mg} \%$, and from 150 to $300 \mathrm{mg} \%$ caused a significant increase in the rate of insulin secretion. The pan- creas from obese mice on a restricted diet showed no glucose effect on insulin secretion on increasing the concentration from $60 \mathrm{mg} \%$ to $150 \mathrm{mg} \%$, but an increase in the presence of $300 \mathrm{mg} \%$.

(ii) Influence of glucose, theophylline, leucine and arginine. In another series of experiments the effects of glucose, theophylline, leucine and arginine were studied and the results are given in Table 2 . In these experiments the insulin secreted in three twenty minute periods was assayed as described above. The stimulant tested was added in the third twenty minute period of incubation and the "effect ratio" was calculated from the amount of insulin secreted in this period divided by the amount of insulin secreted in the preceding period, i.e. before addition of the stimulant [26]. This ratio was compared to the "control ratio" calculated from the corresponding values obtained in these incubation periods without addition of any stimulant. These experiments therefore give data in which the same pieces of pancreas are incubated with and without stimulant and therefore the problem of the biological variation between different pancreases is obviated.

The results obtained with theophylline are of interest in two respects. Firstly, the stimulation observed with theophylline in the lean mouse pancreas in the presence of $300 \mathrm{mg} \%$ glucose was taken as an indication of the validity of the technique and secondly, the $\mathrm{ob} / \mathrm{ob}$ mouse pancreas showed stimulation of insulin with theophylline both in the absence and presence of glucose. Thus the very high rate of insulin secretion already observed in the presence of $300 \mathrm{mg} \%$ glucose was further increased by a cyclic AMP phosphodiesterase inhibitor.

These results confirm the previous finding that increasing the glucose concentration does not maintain a high rate of insulin secretion in the pancreas of the lean mice but does in the ob/ob and the ob/ob RD mice.

An in vitro effect of amino acids on insulin secretion has been observed before [10]. In the present work the influence of the two amino acids leucine and arginine on insulin secretion from ob/ob, ob/ob RD and lean mice has been compared in the absence of glucose using the effect ratio criterion as described above, and the results are included in Table 2 . It is of interest that under these conditions leucine stimulated insulin secretion from the pancreas of all three groups of mice studied, whereas arginine stimulated insulin secretion in the absence of glucose from the lean mouse pancreas but not from the ob/ob mouse pancreas.

(iii) Perifusion studies. The last series of experiments were carried out using the perifusion technique and typical results are shown in Figs. 2,3 and 4 . In the experiments shown in Fig. 2, perifusion commenced with $150 \mathrm{mg} \%$ glucose in the perifusion fluid and in each case there was a rapid initial output of insulin which returned to a low level at $40 \mathrm{~min}$. The glucose concentration was then increased to $300 \mathrm{mg} \%$ and the results show that in both the ob/ob mouse pancreas 
and in the pancreas of the ob/ob RD there was a second rapid insulin output lasting for 20 to $30 \mathrm{~min}$. In the lean mice the initial insulin output was rapidly falling after perifusing with $150 \mathrm{mg} \%$ of glucose for $40 \mathrm{~min}$. but when the glucose concentration was increased to 300 $\mathrm{mg} \%$ it was maintained for a further twenty minute period.

Fig. 3 shows the results of adding leucine after 40 min to the perifusion system in the presence of $150 \mathrm{mg}$

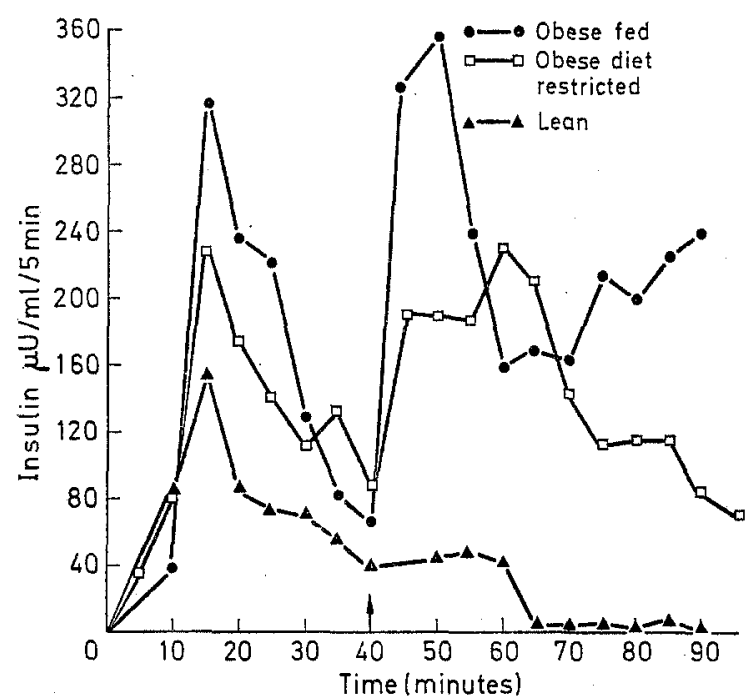

Fig. 2. Influence of increasing glucose concentration on the secretion of insulin in perifused pieces of pancreas from ob/ob, ob/ob RD and lean mice. Perifusion fluid contained $150 \mathrm{mg} \%$ glucose at the start of the experiment, and this was increased to $300 \mathrm{mg} \%$ after $40 \mathrm{~min}$. The rate of flow was $0.2 \mathrm{ml} / \mathrm{min}$; results expressed as $\mu \mathrm{U}$ insulin secreted in $5 \mathrm{~min}$

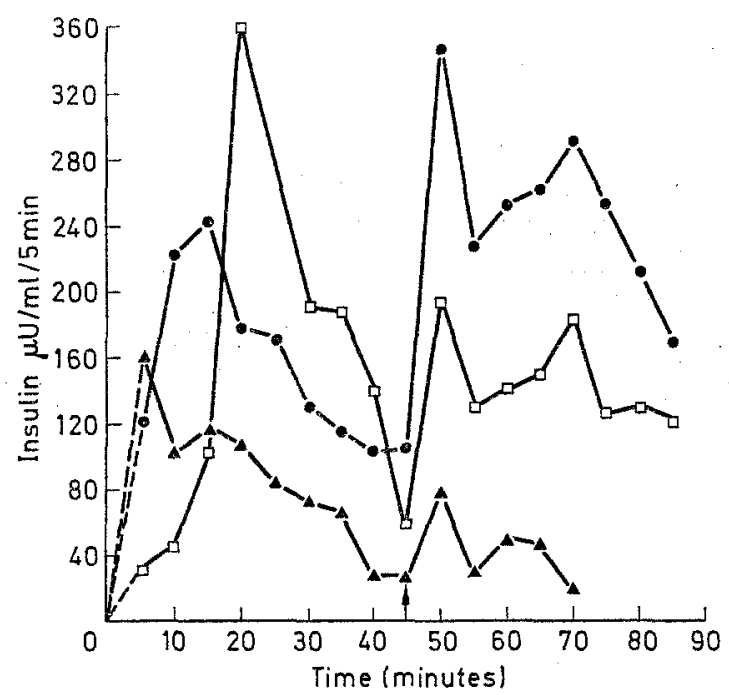

Fig. 3. Influence of leucine on the secretion of insulin in perifused pieces of pancreas from ob/ob, ob/ob RD and lean mice. Perifusion fluid contained $150 \mathrm{mg} \%$ glucose at the start of the experiment, and $10 \mathrm{mM}$ leucine was added after 40 min. Conditions and key as in Fig. 2
$\%$ glucose. Although the amount of insulin secreted under the stimulus of amino acids was much greater from the pancreases of the ob/ob and ob/ob RD mice than from the lean mice the qualitative biphasic response which has been reported by other investigators $[5,20]$ was observed in all three groups.

Fig. 4 shows the increased stimulating effect of arginine on insulin release from the pancreas of the $\mathrm{ob} / \mathrm{ob}$ mouse as the glucose concentration is increased.

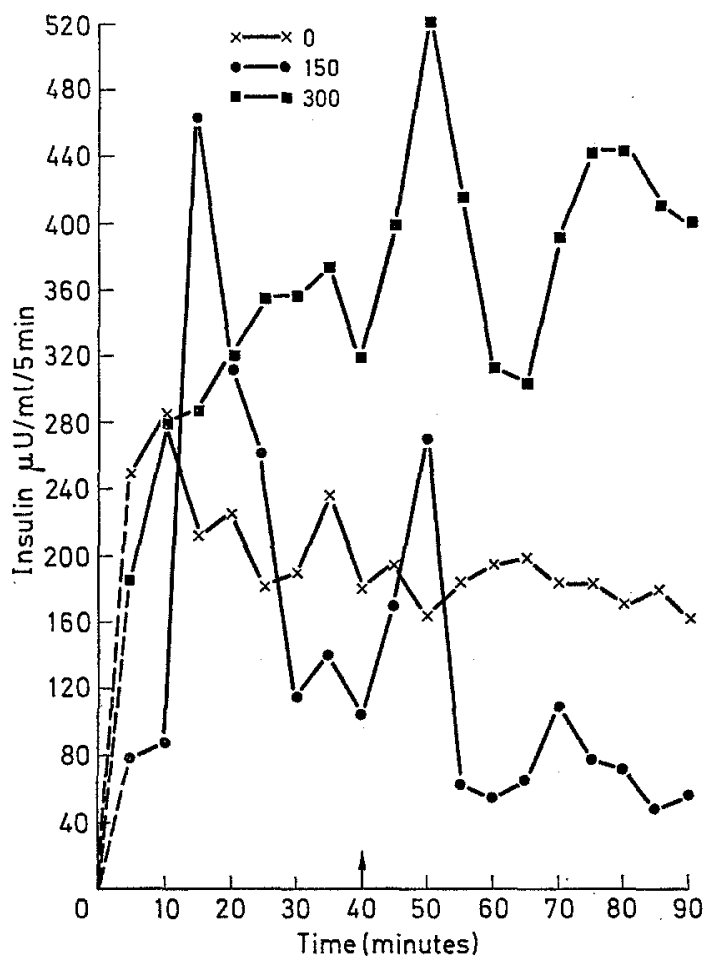

Fig. 4. Influence of arginine on the secretion of insulin in perifused pieces of pancreas from ob/ob mice, at varying glucose concentrations. $10 \mathrm{mM}$ arginine added after

$40 \mathrm{~min}$. Glucose concentrations $\mathrm{mg} \%$ as given in key

In the absence of glucose there was no stimulatory effect of arginine, confirming the findings reported in Table 2.

The mechanism of the influence of amino acids on insulin secretion has not been clarified and the depen. dence on glucose for this effect has given conflicting data which could be explained by differences in the species under investigation, the relative concentration of amino acids and glucose studied or the technique used to measure insulin secretion. Thus for example it has been reported [23] that in pieces of rabbit pancreas, leucine but not arginine stimulates insulin release in the absence of glucose; it was further reported [10] that the stimulation of insulin secretion by arginine in pieces of rabbit pancreas depends on the presence of glucose, although an effect of arginine on insulin secretion in the absence of glucose has been obtained in the perfused rat pancreas [20]. 
c) General Conclusions

In conclusion it would appear that there are marked quantitative differences in the response of the pancreas of the obese mouse and the lean mouse, in that the former show a very large and sustained increase in insulin secretion in the presence of high glucose concentrations which is not observed in the pancreas of the lean mice.

The lack of a significant glucose effect on insulin glucose concentrations and to an increased insulin content of the pancreas) as the pancreas of the obese mice maintained on a restricted diet, which have normal blood glucose levels and a normal pancreatic insulin content, respond similarly to the obese mice fed $a d$ libitum. This supports the view that an abnormal response of the pancreas, which manifests itself by an increased glucose dependence, is a primary defect in the ob/ob syndrome.

Table 2. Influence of some stimulants of insulin secretion on the pancreas of $o b / o b, o b / o b$ $R D$ and lean mice. "Control Ratio" and "Effect Ratio" explained in text and p values are for significant differences between those ratios $p \gtrless 0.05$

\begin{tabular}{|c|c|c|c|c|c|c|}
\hline \multirow[b]{2}{*}{ Animals } & \multirow{2}{*}{$\begin{array}{l}\text { Glucose } \\
\text { conc. } \\
\text { initially } \\
\mathrm{mg} \%\end{array}$} & \multirow[b]{2}{*}{$\begin{array}{l}\text { Stimulant added } \\
\text { in Period } 3\end{array}$} & \multicolumn{4}{|c|}{ Insulin secretion } \\
\hline & & & $\begin{array}{l}\text { No. of } \\
\text { expts. }\end{array}$ & 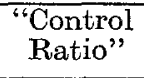 & $\begin{array}{l}\text { Effect } \\
\text { Ratio" }\end{array}$ & $\begin{array}{l}\text { Signifi- } \\
\text { cance }\end{array}$ \\
\hline Lean & 150 & $300 \mathrm{mg} \%$ glucose & 9 & 0.73 & 0.87 & NS \\
\hline ob/ob & 150 & & 7 & 0.62 & 1.03 & $p<0.05$ \\
\hline $\mathrm{ob} / \mathrm{ob} \mathrm{RD}$ & 150 & " & 9 & 0.83 & 1.62 & $p<0.05$ \\
\hline Lean & 300 & $10 \mathrm{mM}$ theophylline & 3 & 0.65 & 1.11 & $p<0.02$ \\
\hline $\mathrm{ob} / \mathrm{ob}$ & 0 & & 5 & 0.57 & 1.15 & $p<0.05$ \\
\hline$o b / o b$ & 150 & 3 & 6 & 0.62 & 1.92 & $p<0.05$ \\
\hline$o b / o b$ & 300 & $"$ & 5 & 0.79 & 1.51 & $p<0.02$ \\
\hline Lean & 0 & $10 \mathrm{mM}$ Leucin $\theta$ & 3 & 0.70 & 1.50 & $p<0.01$ \\
\hline $\mathrm{ob} / \mathrm{ob}$ & 0 & , & 6 & 0.57 & 0.98 & $p<0.05$ \\
\hline ob/ob RD & 0 & $"$ & 3 & 0.58 & 2.13 & $p<0.001$ \\
\hline Lean & 0 & $10 \mathrm{mM}$ Arginine & 5 & 0.70 & 2.09 & $p<0.01$ \\
\hline $\mathrm{ob} / \mathrm{ob}$ & 0 & & 6 & 0.57 & 0.77 & NS \\
\hline
\end{tabular}

secretion in incubated pieces of mouse pancreas does not conform with some findings of other investigators using isolated mouse islets $[3,6]$. Lernmark, Hellman and Coore (1969) [19] used whole pancreas of $18 \mathrm{~h}$ starved lean mice (of the Bar Harbor strain) and reported an approximately four fold increase in insulin secretion on increasing the glucose concentration of the medium in a $30 \mathrm{~min}$ incubation period; the authors however state that experiments in which no glucose stimulation was observed were discarded. Malaisse and Malaisse-Lagae (1968) [21] have reported wide variations in the response to glucose of insulin secretion from pieces of pancreas of different animal species, and the effect on the mouse pancreas was in fact very small. These authors comment on the fact that the basal insulin secretion from mouse pancreas, in the absence of glucose, is high compared to the rat and Chinese Hamster.

It is of interest in this connection that, using the perfused pancreas of the lean and ob/ob mice, it was shown [18] that increasing the glucose concentration from $2.75 \mathrm{mM}$ to $11 \mathrm{mM}$ has only a small effect on insulin output in the lean mouse, whereas there is a much more marked and sustained effect in the ob/ob mouse pancreas. From the present results it would. appear that the difference in the response of the pancreas of the ob/ob and lean mice is not dependent on the hyperphagia in the former (leading to high blood
Acknowledgement. We are grateful to the Science Research Council and Beecham Research Laboratories for a CAPS Research Studentship to M.E. Newman, and to the Wellcome Trust for support.

\section{References}

1. Abraham, R.R., Beloff-Chain, A.: Hormonal control of intermediary metabolism in obese hyperglycaemic mice. I. The sensitivity and response to insulin in adipose tissue and muscle in vitro. Diabetes $\mathbf{2 0 , 5 2 2 -}$ $534(1971)$

2. Abraham, R.R., Dade, E., Elliott, J., Hems, D.A.: Hormonal control of intermediary metabolism in obese hyperglycaemic mice. II. Levels of plasma free fatty acids and immunoreactive insulin and liver glycogen. Diabetes 20, 535-541 (1971)

3. Ashcroft, S.H., Bassett, J.M., Randle, P.J.: Insulin secretion mechanisms and glucose metabolism in isolated islets. Diabetes 21, $538-545(1972)$

4. Bray, G.A., York, D.A.: Genetically transmitted obesity in rodents. Phys. Ther. rev. 51, 598-646 (1971)

5. Burr, T.M., Stauffacher, W., Balant, L., Renold, A.E., Grodsky, G.M.: Regulation of insulin release in perifused pancreatic tissue. Acta. diab. lat. 6, $580-$ 596 (1969)

6. Coll-Garcia, E., Gill, J.R. : Insulin release by isolated pancreatic islets of the mouse incubated in vitro. Diabetologia 5, 61-66 (1969)

7. Coore, H.G., Randle, P.J.: Regulation of insulin secretion studied with pieces of rabbit pancreas incubated in vitro. Biochem. J. 93, 66-78 (1964) 
8. Curry, D.L., Bennett, L.L., Grodsky, G.M.: Dynamics of insulin secretion by the perfused rat pancreas. Endocrinology 83, 572-584 (1968)

9. Edgar, P., Rabinowitz, D., Merimee, T.J.: Effects of amino acids on insulin release from excised rabbit pancreas. Endocrinology 84, 835-843 (1969)

10. Edgar, P., Rabinowitz, D., Merimee, T.J., Almogela, E.: Effect of arginine on insulin release in vitro. Metabolism 18, 84-86 (1969)

11. Findlay, J.A., Rookledge, K.A., Beloff-Chain, A., Lever, J. D. : A combined biochemical and histological study on the islets of Langerhans in the genetically obese hyperglycaemic mice and in the lean mouse, including observations on the effects of streptozotocin. J. Endocr. 56, 571-583 (1973)

12. Genuth, S.M.: Hyperinsulinism in mice with genetically determined obesity. Endocrinology 84, 386391 (1969)

13. Heding, L. G.: Radioimmunological determination of pancreatic and gut glucagon in plasma. Diabetologia $7,10-15(1971)$

14. Hellman, B.: Studies in obese-hyperglycaemic mice. Ann. N.Y. Acad. Sci. 131, $541-558$ (1965)

15. Howell, S.L., Taylor, K.W.: The secretion of newly synthesized insulin in vitro. Biochem. J. 102, 922-927 (1967)

16. Ingalls, A.M., Dickie, M.M., Snell, G.D.: Obese, a new mutation in the house mouse. J. Hered. 41, $317-318(1950)$

17. Kenny, A.J.: Extractable glucagon of the human pancreas. J. clin. Endocr. 15, 1089-1105 (1955)

18. Laube, H., Fussgänger, R.D., Pfeiffer, E.F.: The effect of a $\beta$-adrenergic blocker on insulin release from the isolated perfused pancreas of the obese mice. J. Endocr. 55, 209-210 (1972)

19. Lernmark, A., Hellman, B., Coore, H.G.: Effect of gastrin on the release of insulin. J. Endocr. 43, 371$375(1969)$

20. Levin, S.R., Grodsky, G.M., Hagua, R., Smith, D.F., Forsham, P.H.: Relationships between arginine and glucose in the induction of insulin secretion from the isolated perfused rat pancreas. Endocrinology 90, $624-631$

21. Malaisse, W.J., Malaisse-Lagae, F.: Effets du glucose sur la sécrétion pancréatique d'insuline in vitro, dans différentes espèces de Rongeurs. Ann. Endocr. (Paris) 29, 501-505 (1968)

22. Malaisse, W.J., Malaisse-Lagae, F., Coleman, D.L.: Insulin secretion in experimental obesity. Metabolism. 17, 802-807 (1968)

23. Milner, R.D.G.: The mechanism by which leucine and arginine stimulate insulin release in vitro. Biochim. biophys. acta. (Amst.) 192, 154-156 (1969)

24. Petersson, B., Hellman, B.: Long term effects of restricted caloric intake on pancreatic islet tissue in obese hyperglycaemic mice. Metabolism 11, 342-348 (1962)

25. Stauffacher, W., Lambert, A.E., Vecchio, D., Renold, A.E. : Measurements of insulin activities in pancreatic serum of mice with spontaneous ("obese" and "New Zealand Obese") and induced (goldthioglucose) obesity and hyperglycaemia, with considerations on the pathogenesis of the spontaneous syndrome. Diabetologia $3,230-237$ (1967)

26. Turner, D.S.: Intestinal hormones and insulin release. In vitro studies using rabbit pancreas. Horm. Metab. Res. 1, 168-174, (1969)

27. Wrenshall, C.A., Andrews, S.B., Mayer, J.: High levels of pancreatic insulin co-existent with hyper. plasia and degranulation of cells in mice with here. ditary obese-hyperglycaemic syndrome. Endocrino. $\operatorname{logy} .56,335-340$ (1955)

Dr. A. Beloff-Chain

Reader in Biochemistry

Department of Biochemistry

Imperial College of Science

and Technology

London S.W. 7

England. 